\title{
Dietary Maillard reaction products and their fermented products reduce cardiovascular risk in an animal model
}

\author{
N. S. Oh, ${ }^{*}$ M. R. Park, $†$ K. W. Lee,† S. H. Kim, $\dagger^{1,2}$ and Y. Kim $\ddagger^{1,2}$ \\ ${ }^{*}$ R\&D Center, Seoul Dairy Cooperative, Ansan, Kyunggi 425-839, South Korea \\ †Division of Food Bioscience and Technology, College of Life Science and Biotechnology, Korea University, Seoul 136-701, South Korea \\ $\ddagger B K 21$ Plus Graduate Program, Department of Animal Science and Institute Agricultural Science and Technology, Chonbuk National University, \\ Jeonju, 561-756, Korea
}

\begin{abstract}
This study examined the effects of Maillard reaction products (MRP) and MRP fermented by lactic acid bacteria on antioxidants and their enhancement of cardiovascular health in ICR mouse and rat models. In previous in vitro studies, the selected lactic acid bacteria were shown to significantly affect the activity of MRP. The expression of genes (e.g., superoxide dismutase, catalase, and glutathione peroxidase) related to antioxidant activity was upregulated by Maillard-reacted sodium caseinate (cMRP), and cMRP fermented by Lactobacillus fermentum H9 (F-cMRP) synergistically increased the expression of catalase and superoxide dismutase when compared with the high-cholesterol-diet group. Bleeding time, the assay for determination of antithrombotic activity, was significantly prolonged by Maillard-reacted whey protein concentration (wMRP) and wMRP fermented by Lactobacillus gasseri H10 (F-wMRP), similar to the bleeding time of the aspirin group (positive control). In addition, the acute pulmonary thromboembolism-induced mice overcame severe body paralysis or death in both the wMRP and the F-wMRP groups. In the serum-level experiment, cMRP and F-cMRP significantly reduced the serum total and low-density lipoprotein cholesterol levels and triglycerides but had only a slight effect on high-density lipoprotein cholesterol. The levels of aspartate transaminase and alanine transaminase also declined in the cMRP and F-cMRP intake groups compared with the highcholesterol-diet group. In particular, F-cMRP showed the highest reducing effects on triglycerides, aspartate transaminase, and alanine transaminase. Moreover, the expression of cholesterol-related genes in the FcMRP group demonstrated greater effects than for the cMRP group in the level of cholesterol $7 \alpha$-hydroxylase
\end{abstract}

\footnotetext{
Received January 5, 2015.

Accepted March 26, 2015.

${ }^{1}$ These authors contributed equally to this work.

${ }^{2}$ Corresponding authors: saehkim@korea.ac.kr and ykeys2584@ jbnu.ac.kr
}

(CYP7A1), 3-hydroxy-3-methylglutaryl-CoA reductase $(H M G R)$, and low-density lipoprotein receptors compared with the high-cholesterol-diet group. The protective role of cMRP and F-cMRP in the high-cholesterol group may have been the result of an antioxidative defense mechanism that regulated cholesterol synthesis and metabolism. Therefore, F-cMRP and cMRP have the potential to play preventive and therapeutic roles in the management of cardiovascular disease.

Key words: prevention of cardiovascular disease, antioxidant activity, lactic acid bacteria, Maillard reaction, in vivo study

\section{INTRODUCTION}

Coronary heart disease continues to be a common cause of human death in developed countries. Many epidemiological and experimental studies have reported high correlations between serum cholesterol levels, especially for low-density lipoprotein (LDL) cholesterol, and incidences of coronary heart disease (Akalin et al., 1997; Park et al., 2008). Several studies have suggested that probiotics or fermented products have hypocholesterolemic effects in humans and rats (Hepner et al., 1979; Grunewald, 1982; Jaspers et al., 1984). The hypocholesterolemic effects of fermented products are caused by the inhibition of dietary cholesterol absorption and the suppression of endogenous cholesterol synthesis. Several genes are related to cholesterol synthesis and metabolism, such as LDLr, HMGR, and CYP 7A1. Controlling expression of these genes is a major factor in the prevention of atherosclerosis and hypercholesterolemia. Low-density lipoprotein is directly involved in the development of atherosclerosis because of accumulation of LDL cholesterol in the blood. Low-density lipoprotein receptor has the ability to regulate LDL cholesterol, and CYP7A1, a cholesterol-metabolizing enzyme, results in hypocholesterolemic effects. Fermentation enhances assimilation of cholesterol by bile acid and leads to the reduction of absorbable cholesterol, which directly affects serum cholesterol levels. Atherosclerosis, one of the major cardiovascular diseases, is 
modulated through diet, cellular oxidative stress, and oxidant status. In particular, oxidatively modified LDL plays an important role in prevention of atherosclerosis (Witztum, 1991). Wang et al. (2004) reported that an antioxidative defense mechanism, caused by the induction of antioxidant enzyme activities, protected against the development of atherosclerosis. The primary antioxidant enzymes superoxide dismutase (SOD), catalase (CAT), and glutathione peroxidase (GSH-Px) protect against molecular and cellular damage caused by reactive oxygen species. Once vascular disease occurs, endogenous agonists such as ADP, collagen, and thrombin activate platelets, which adhere to the site of an injury (Packham and Mustard, 2005). When blood vessels are damaged, platelet aggregation rapidly occurs, and thrombosis leads to complications associated with arteriosclerosis, which is a peripheral cardiovascular disease (Corti et al., 2003).

Previously in an in vitro study, we reported that Maillard reaction products (MRP) produced from milk proteins and MRP fermented by Lactobacillus gasseri H10, for the purpose of antithrombosis, and fermented by Lactobacillus fermentum $\mathrm{H} 9$, for the reduction of cholesterol, were demonstrated to have important anticardiovascular activities (Oh et al., 2014). The aim of this study was to examine and verify the effects of MRP and fermented MRP on cardiovascular parameters in animal model, based on the results of our previous study (Oh et al., 2014).

\section{MATERIALS AND METHODS}

\section{Chemicals}

Whey protein concentrates and sodium caseinate were obtained from Davisco Foods International Inc. (Le Sueur, MN) and Kerrygold (Dublin, Ireland), respectively, and lactose monohydrate was purchased from Junsei Chemical Co. (Tokyo, Japan). The chemicals, including collagen and epinephrine, used in this study were purchased from Sigma Chemical Co. (St. Louis, MO). Disodium monophosphate and monosodium phosphate were from Showa Chemicals (Osaka, Japan). All chemicals used were of analytical grade.

\section{Preparation of MRP and Fermentation}

Whey protein concentrates and sodium caseinate and lactose were dissolved in $0.1 \mathrm{M}$ sodium phosphate buffer $(\mathrm{pH} 7.4)$ as 1:5 weight ratio of protein $(10 \mathrm{mg})$ and sugar $(50 \mathrm{mg})$. The reaction was allowed to proceed at $55^{\circ} \mathrm{C}$ with $60 \mathrm{rpm}$ in shaking water bath for a day. The $\mathrm{pH}$ value was not controlled during the reaction.
And then, reaction mixtures were extensively dialyzed against $0.1 M$ sodium phosphate buffer (pH 7.4) 3 times within $24 \mathrm{~h}$ and were lyophilized. Lactic acid bacteria used in this study was obtained from the Food Microbiology Laboratory, Division of Food Bioscience and Technology, Korea University (Seoul, Korea). Lactic acid bacteria was activated successively 3 times in de Man, Rogosa, and Sharpe broth (Difco Laboratories, Detroit, MI) at $37^{\circ} \mathrm{C}$ for $18 \mathrm{~h}$ before use. Stock culture was maintained at $-80^{\circ} \mathrm{C}$ with sterile $50 \%$ ( $\mathrm{vol} / \mathrm{vol}$ ) glycerol as a cryoprotectant. The strains were subcultured 3 times before use. Fermentation of MRP was performed in MRP solution that contained 3\% MRP and $2 \%$ glucose. A total of $10^{9} \mathrm{cfu} / \mathrm{mL}$ bacterial cells were inoculated into MRP solution and incubated at $37^{\circ} \mathrm{C}$ for $48 \mathrm{~h}$. After centrifugation of the fermented MRP in a Hitachi CR-21G rotor R20A (Hitachi Ltd., Tokyo, Japan) at $28,000 \times g$ for $10 \mathrm{~min}$ at $4^{\circ} \mathrm{C}$, the supernatant was freeze-dried, and the powder was used to be fed for the experiment.

\section{Animal Model}

Sixty ICR mice (Samtako Bio Korea Co. Ltd., Gyeonggi-do, South Korea) were obtained at 5 wk of age with an initial average weight of $29 \mathrm{~g}$ for determination of antithrombotic effect by the slightly modified method of Kim and Lee (2006). A total of 4 treatment groups $(\mathrm{n}=15)$ were fed the following diets for a week after a week adaptation: normal diet plus PBS as negative control (10 $\mathrm{mL} / \mathrm{kg}$ per day), normal diet plus aspirin as positive control (50 mg/kg per day), normal diet plus Maillard-reacted whey protein concentration (wMRP; $1,500 \mathrm{mg} / \mathrm{kg}$ per day), and normal diet plus fermented wMRP by L. gasseri H10 (F-wMRP; 1,500 $\mathrm{mg} / \mathrm{kg}$ per day).

To determine the antioxidant activity and cholesterolreduction effect of fermented Maillard-reacted sodium caseinate (cMRP), 60 rats were obtained at 6 wk of age with an initial average weight of $152.3 \mathrm{~g}$. A total of 6 treatment groups $(\mathrm{n}=10)$ were fed the following experimental diets for 8 wk after a week adaptation: normal diet plus PBS (ND group, $10 \mathrm{~mL} / \mathrm{kg}$ per day), high-cholesterol diet plus PBS (HCD group, $10 \mathrm{~mL} /$ $\mathrm{kg}$ per day), high-cholesterol diet plus simvastatin (SV group, $50 \mathrm{mg} / \mathrm{kg}$ per day), high-cholesterol diet plus $L$. fermentum H9 (H9 group, 1,500 mg/kg per day), highcholesterol diet plus cMRP (cMRP group, 1,500 mg/ $\mathrm{kg}$ per day), and high-cholesterol diet plus fermented cMRP by L. fermentum H9 (F-cMRP group, 1,500 $\mathrm{mg} / \mathrm{kg}$ per day). The animals were individually housed in mesh-bottom stainless steel cages in a temperaturecontrolled room $\left(22.2^{\circ} \mathrm{C}\right)$, with 12 -h light-12-h dark lighting cycles. The BW of rats were checked every 
Table 1. The reverse-transcription PCR primers and PCR conditions used in this study

\begin{tabular}{|c|c|c|c|c|}
\hline \multirow{3}{*}{$\frac{\text { Gene }}{S O D}$} & \multicolumn{2}{|c|}{ Sequence $\left(5^{\prime} \text { to } 3^{\prime}\right)^{1}$} & \multirow{2}{*}{$\begin{array}{c}\begin{array}{c}\text { Product } \\
\text { size, bp }\end{array} \\
342\end{array}$} & \multirow{2}{*}{$\begin{array}{l}\begin{array}{l}\text { Accession } \\
\text { number }\end{array} \\
\text { NM_017051.2 }\end{array}$} \\
\hline & $\mathrm{F}$ & TTG GCC TTC TTG TTC TAC GG & & \\
\hline & $\mathrm{R}$ & GCC CTC CAG ACT GAA ATA GG & & \\
\hline \multirow[t]{2}{*}{$C A T$} & $\mathrm{~F}$ & AGG TCA CCC ACG ATA TCA CC & 320 & NM_012520.2 \\
\hline & $\mathrm{R}$ & AGA CTC GGG ACG AAG ACT CC & & \\
\hline \multirow[t]{2}{*}{$G S H-P x$} & $\mathrm{~F}$ & GCC CTC CCA CTG CAG AAC TCC & 193 & NM_030826.3 \\
\hline & $\mathrm{R}$ & GCT GCC TGC CGC CTC ATG & & \\
\hline \multirow[t]{2}{*}{$H M G R$} & $\mathrm{~F}$ & GTT CTT TCC GTG CTG TGT TCT GGA & 461 & NM_013134.2 \\
\hline & $\mathrm{R}$ & CTG ATA TCT TTA GTG CAG AGT GTG GCA C & & \\
\hline \multirow[t]{2}{*}{ CYP $7 A 1$} & $\mathrm{~F}$ & CAA GAA CCT GTA CAT GAG GGA C & 214 & NM_012942.2 \\
\hline & $\mathrm{R}$ & CAC TTC TTC AGA GGC TGC TTT C & & \\
\hline \multirow[t]{2}{*}{$L D L r$} & $\mathrm{~F}$ & ATG AGT CCC CAG AGA CAT GC & 357 & NM_175762.2 \\
\hline & $\mathrm{R}$ & CGT CAA CAC AGT CGA CAT CC & & \\
\hline \multirow[t]{2}{*}{$\beta$-Actin } & $\mathrm{F}$ & TGT GAT GGT GGG AAT GGG TCA G & 514 & NM_031144.3 \\
\hline & $\mathrm{R}$ & TTT GAT GTC ACG CAC GAT TTC C & & \\
\hline
\end{tabular}

${ }^{1} \mathrm{~F}=$ forward; $\mathrm{R}=$ reverse

week during the experiment period. Animals had ad libitum access to water.

\section{Pathological Histology in Liver Tissue}

Pathological histology was evaluated according to previously described methods with modifications (Renju et al., 2014). After removal of the rat liver, tissues were fixed in formaldehyde. The formaldehyde-fixed hepatic-tissue samples were processed for histological study. Paraffin-embedded tissue sections were stained with hematoxylin and eosin. The tissue samples were then examined and photographed under a light microscope for histopathological changes.

\section{Measurement of mRNA Expression}

Frozen liver tissues were homogenized in ice-cold 50 $\mathrm{m} M$ phosphate buffer. The homogenate was centrifuged at $13,000 \times g$ for $15 \mathrm{~min}$ at $4^{\circ} \mathrm{C}$. Then, the supernatant was collected in a fresh 1.5-mL tube and measured for mRNA expression. Total RNA were extracted from liver cells using a modified acid-phenol extraction protocol (Nuyts et al., 2001). Then, cDNA was generated using Superscript transcriptase III (Invitrogen Co., Carlsbad, CA). After cDNA synthesis, PCR was performed in denaturation for $30 \mathrm{~s}$ at $94^{\circ} \mathrm{C}$, annealing for $30 \mathrm{~s}$ at the temperature depending on the primers shown in Table 1 , and extension for $30 \mathrm{~s}$ at $72^{\circ} \mathrm{C}$ for 30 cycles. The primer sequences used for PCR are as Table 1. Expression of $S O D, C A T$, and GSH-Px was determined for antioxidant activity, and expression of HMGR, CYP $7 A 1$, and $L D L r$ was determined for cholesterol-reduction activity. The reverse-transcription PCR products were electrophoresed in a $2 \%$ agarose gel and visualized by ethidium bromide staining. All results were finally determined after correction with $\beta$-actin, housekeep- ing gene expression with the PCR bands calculated by ImageJ software.

\section{Antithrombotic Activity in ICR Mice}

The tail transection bleeding time was determined according to the method of Dejana et al. (1979). The mouse tail was transected at $5 \mathrm{~mm}$ from the tip, and it was immediately immersed into warmed $\left(37^{\circ} \mathrm{C}\right)$ saline. The bleeding time was determined as the time from the tail transection to the moment the bleed flow stopped for more than $60 \mathrm{~s}$. Bleeding time beyond $600 \mathrm{~s}$ was considered as cut-off time for the purpose of statistical analysis.

Antithrombotic activity was also evaluated in the acute pulmonary thromboembolism (APT)-induced mouse model according to the method of DiMinno and Silver (1983). The ICR mice were used after overnight fasting. A mixture solution of collagen $(114 \mu \mathrm{g}$ per mouse) and epinephrine (1.83 $\mu \mathrm{g}$ per mouse) was injected into the tail vein at a rate of about $20 \mu \mathrm{L} / \mathrm{s}$ to induce pulmonary thrombosis. As used here, paralysis refers to loss of function of the hind limbs for more than $15 \mathrm{~min}$. The number of dead or paralyzed mice was recorded up to $15 \mathrm{~min}$, and the percentage of protection was calculated with the following equation:

$$
\begin{gathered}
\text { percentage protection }(\%)= \\
(1-\text { dead or paralyzed mice/total mice }) \times 100 .
\end{gathered}
$$

\section{Serum Cholesterol and Liver Health Analysis}

Blood samples were collected by cardiac puncture after administration of ketamine-xylazine (90 mg per $\mathrm{kg}$ of BW/10 mg per $\mathrm{kg}$ ). Approximately $1 \mathrm{~mL}$ of blood was taken from each rat, transferred to a $1.5-\mathrm{mL}$ tube, 
and kept on ice for $30 \mathrm{~min}$. Tubes were centrifuged at $2,000 \times g$ for $20 \mathrm{~min}\left(4^{\circ} \mathrm{C}\right)$; serum was collected; and total cholesterol, LDL cholesterol, HDL cholesterol, triglyceride, aspartate transaminase (AST), and alanine transaminase (ALT) were measured using commercially available kits.

\section{Statistical Analysis}

All data were expressed as means \pm standard deviation. Statistical significance for the differences between the groups was assessed using Duncan's multiple range tests. The IBM-SPSS software (version 22.0, Chicago, IL) was used to perform all statistical tests. Values of $P<0.05$ were considered to indicate a significant difference.

\section{RESULTS AND DISCUSSION}

\section{BW of Rats}

The effects of supplementation with a high-cholesterol diet; high-cholesterol diet plus simvastatin; or high-cholesterol diet plus H9, cMRP, or F-cMRP on the weight gain of rats is shown in Table 2. After an 8 -wk administration of each diet, the rats in the HCD group had the highest average weight gains (125\% BW gain compared with the ND group) among the experimental groups. The rats of all sample groups did not gain as much BW as the HCD group did $(P<0.05)$. In particular, intake of F-cMRP significantly inhibited increases in BW at a similar rate to the ND group.

\section{Liver Histopathology of Hypercholesterolemic Rats}

Livers from rats fed 5 different diets were analyzed histologically, and stained sections were analyzed by light microscopy. Figure 1 shows the sections stained with hematoxylin and eosin. Lipid accumulation in the livers of rats fed a high-cholesterol diet was very evident due to the presence of circular lipid droplets on the hematoxylin and eosin-stained sections, when compared with rats fed a normal diet. These lipid inclusions were greatly reduced in both size and number in the livers of all groups of rats supplemented with F-cMRP, cMRP, and H9. These results are supported in a report by Wat et al. (2009) that suggested that HFPL mice (high-fat-fed mice supplemented with phospholipid-rich dairy milk extract) exhibited a decrease in the size and number of lipid droplets.

\section{mRNA Expression of SOD, CAT, and GSH-PX}

The mRNA levels of hepatic antioxidant enzymes were determined using Northern blot analysis. As a loading control, mRNA signals of the antioxidant enzymes were normalized to the $\beta$-actin mRNA signal for each group (Figure 2). The HCD group showed downregulated expression of $C A T, S O D$, and GSH-Px compared with the ND group. On the other hand, all of the mRNA levels of genes in the cMRP and F-cMRP groups were significantly increased and recovered from decreases by the HCD. In particular, the expression of $S O D$ was increased to a significant degree with F-cMRP $(140 \%)$ and cMRP (118\%) compared with the HCD group, but $L$. fermentum H9 had no effect $(P<0.05)$. The levels of $C A T$ expression showed no significant differences among the groups supplemented with $\mathrm{H} 9$, cMRP, and F-cMRP. The expression of GSH-Px was observed to experience a significant effect with increases with cMRP and F-cMRP of 117 and 119\%, respectively, compared with the HCD-fed group, whereas L. fermentum H9 had no effect. Similar results were reported by Ramesh et al. (2009), who found that the mean activities of SOD, CAT, and GSH-Px in hepatic tissue samples were significantly lower in hypercholesterolemia-induced rats compared with normal rats. According to the study by $\mathrm{Xu}$ et al. (2011), treatment with whey protein on

Table 2. Effect of cMRP and fermented cMRP by Lactobacillus fermentum H9 on BW gain (g; means \pm SD) of rats

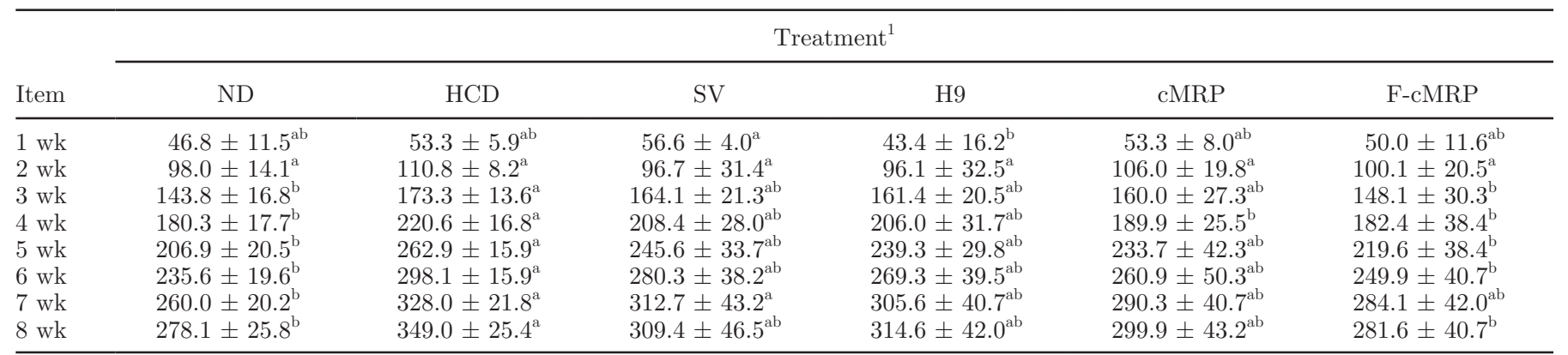

${ }^{\mathrm{a}, \mathrm{b}}$ Data followed by a different superscripts are significantly different $(P<0.05)$.

${ }^{1} \mathrm{ND}=$ normal diet; HCD = high-cholesterol diet; $\mathrm{SV}=$ simvastatin; H9 = L. fermentum $\mathrm{H} 9$; cMRP = Maillard-reacted sodium caseinate; $\mathrm{F}-\mathrm{cMRP}=$ fermented $\mathrm{cMRP}$. 
A

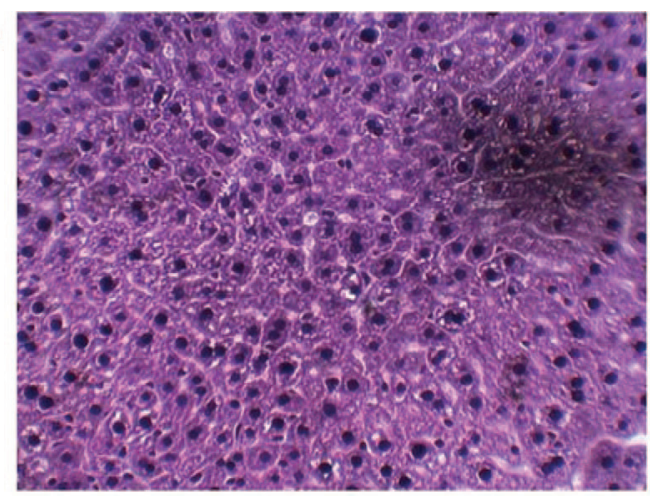

C

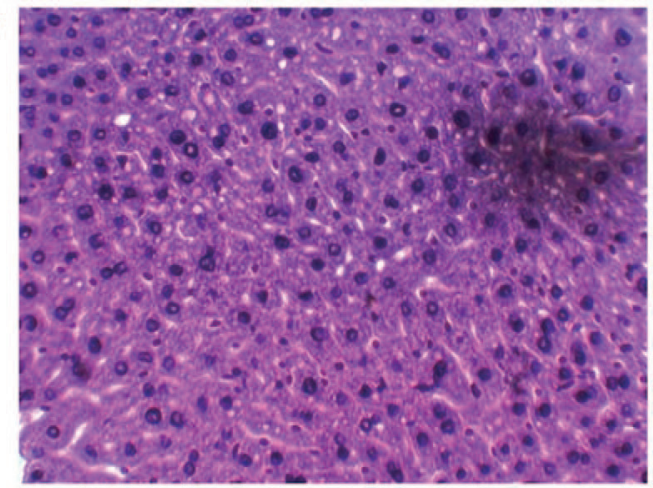

E

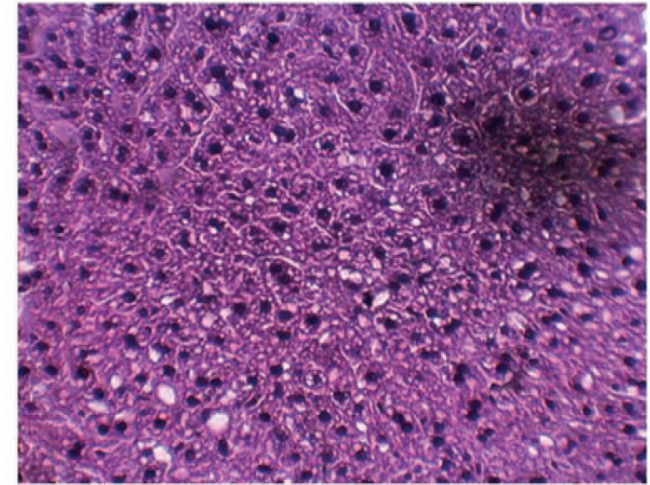

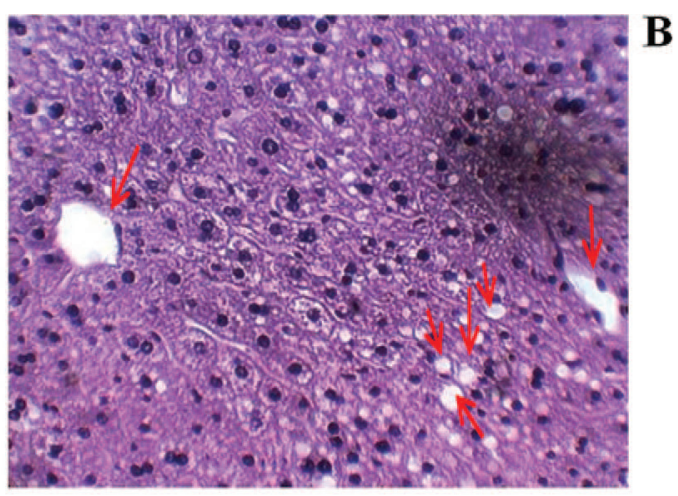

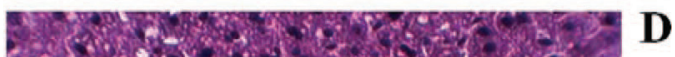

Figure 1. Rat hepatic tissues stained with hematoxylin and eosin (200× magnification). Liver-tissue sections prepared from (A) normal diet, (B) high-cholesterol diet, (C) fermented Maillard-reacted sodium caseinate (cMRP) by Lactobacillus fermentum H9, (D) cMRP, and (E) L. fermentum H9. The arrows indicate the lipid droplets generated. Color version available online.

$\mathrm{C}_{2} \mathrm{C}_{12}$ myoblasts significantly enhanced SOD and CAT activity. Moreover, Wang et al. (2008) reported that supplementation with bovine lactoferrin, a component of milk proteins, improved mRNA expression of $S O D$ and $C A T$, with a significant linear increase $(P<0.01)$ as the dietary bovine lactoferrin level increased. It has been reported that microbial fermentation promotes the effect of substances on antioxidation; supplementation with garlic fermented by Monascus pilosus increased the expression of $S O D$ by $35 \%$ and of $C A T$ by $200 \%$ compared with the control (HCD) group, whereas intake of garlic and M. pilosus alone showed no significant effect (Kuo et al., 2008).
The major intracellular antioxidant defenses include the GSH pool and reactive oxygen species-scavenging enzymes such as CAT, SOD, and GSH-Px. Increased levels of these endogenous enzymes have been shown to protect cells against oxidative damage. This study showed that feeding rats cMRP and F-cMRP for $8 \mathrm{wk}$ resulted in an increase in the mRNA levels of $S O D$, $C A T$, and GSH-Px when compared with rats fed the HCD. The upregulation of the mRNA in rats treated with cMRP and greater expression of $S O D$ in those treated with F-cMRP could be interpreted as an effort to overcome oxidative stress induced by hypercholesterolemia. 
(A)

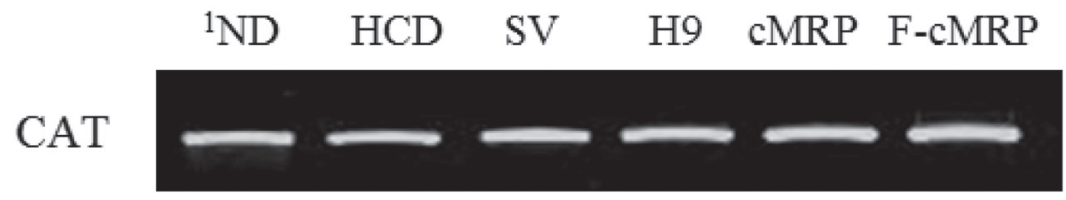

SOD

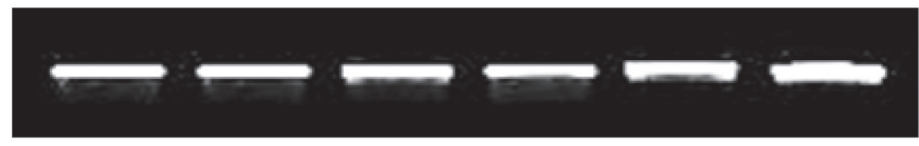

GSH-px

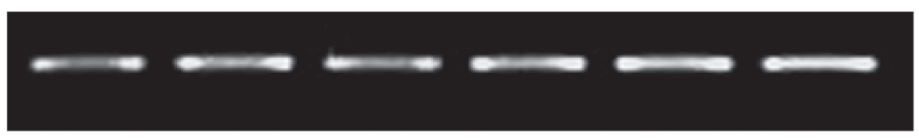

$\beta$-actin

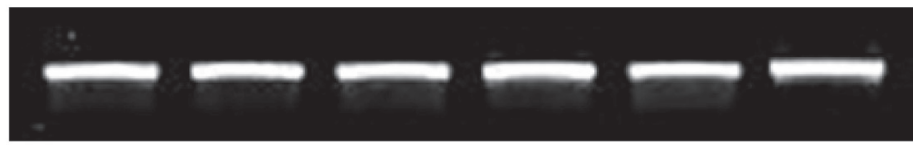

(B)

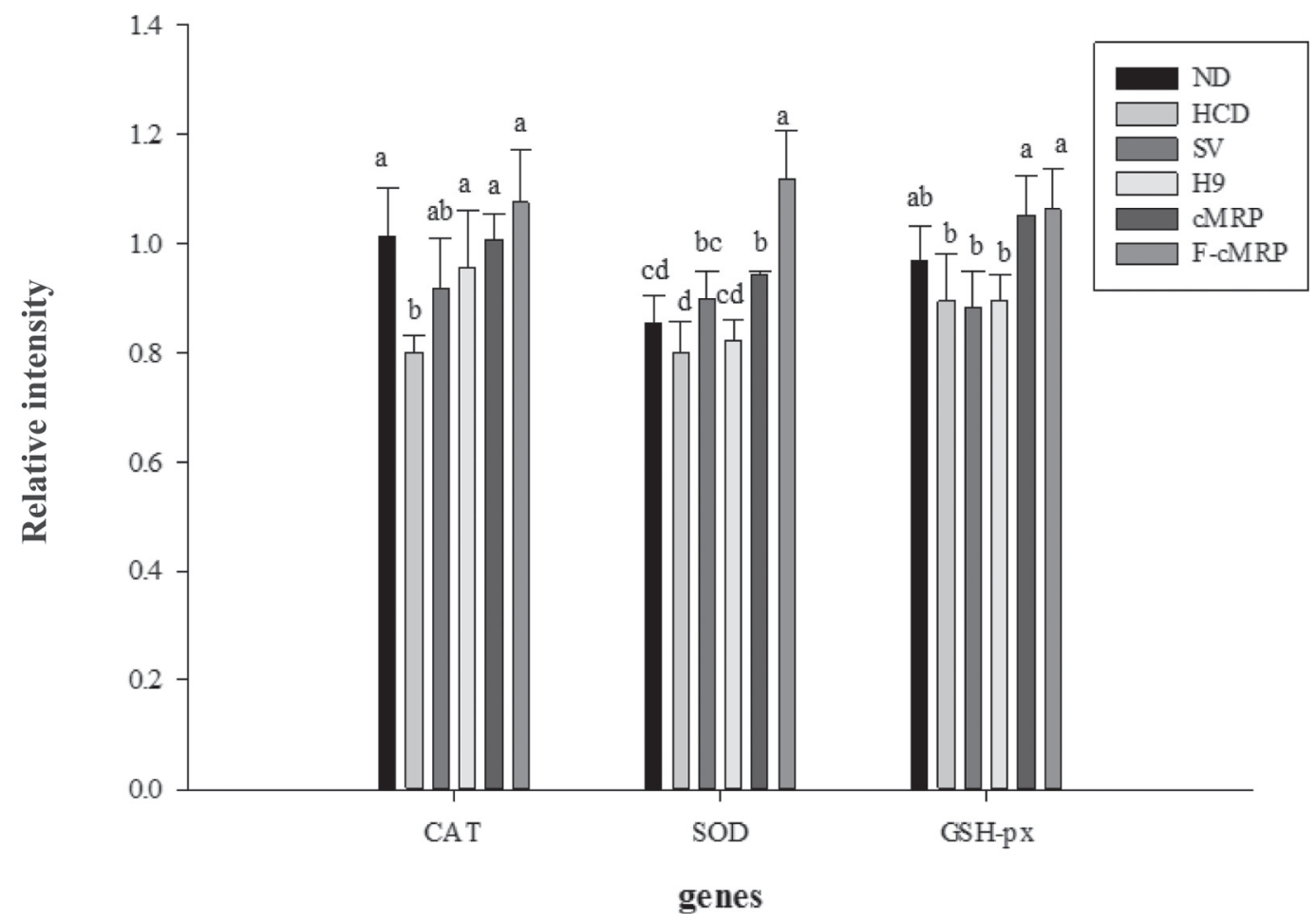

Figure 2. Effect of Maillard-reacted sodium caseinate (cMRP) and fermented cMRP (F-cMRP) by Lactobacillus fermentum H9 (H9) on expression of the antioxidant activity-associated genes ( $S O D, C A T$, and $G S H-P x)$ as (A) semiquantitative reverse-transcription PCR images and (B) relative intensity. Data are expressed as each gene reverse-transcription PCR products normalized to $\beta$-actin products, the arbitrary value of one being assigned to this ratio for ND. Values are expressed as the mean \pm standard deviation $(\mathrm{n}=10)$. ${ }^{\mathrm{a}-\mathrm{d}}$ Data with different letters are significantly different $(P<0.05)$. ND $=$ normal diet; $\mathrm{HCD}=$ high-cholesterol diet; $\mathrm{SV}=$ simvastatin. 
Table 3. Effect of Maillard-reacted whey protein concentration (wMRP) and fermented wMRP (F-wMRP) by Lactobacillus gasseri $\mathrm{H} 10$ on acute pulmonary thromboembolism in mice

\begin{tabular}{lcccc}
\hline Item & PBS (control) & Aspirin & wMRP & F-wMRP \\
\hline Dose, /kg per d & $10 \mathrm{~mL}$ & $50 \mathrm{mg}$ & $1,500 \mathrm{mg}$ & $1,500 \mathrm{mg}$ \\
Paralyzed or dead mice/total & $12 / 14$ & $2 / 15$ & $2 / 15$ & $1 / 15$ \\
Protection, \% & 14.2 & 86.6 & 86.6 & 93.3 \\
\hline
\end{tabular}

\section{Determination of Antithrombotic Activity}

Bleeding times were analyzed in mice after tail-tip amputations to determine the effect of wMRP and FwMRP on hemostasis (Figure 3). The mean bleeding times in the wMRP group and F-wMRP group were $224.00 \pm 31.30 \mathrm{~s}$ and $197.00 \pm 12.04 \mathrm{~s}$, respectively. The PBS (control) group continued to bleed for only $82.60 \pm 10.14 \mathrm{~s}(\mathrm{n}=15)$, at which point the experiments were terminated. When wMRP and F-wMRP were intraperitoneally administered to mice for a 7-d period, bleeding time was significantly prolonged compared with the PBS (control) group, just as in the aspirin group, to $253.20 \pm 24.12 \mathrm{~s}$. In vivo studies of the antithrombotic activities of milk proteins have been reported and agree with the results of this study, in which the $\mathrm{k}$-casein-derived undecapeptide and the lactoferrinderived tetrapeptide had significant antithrombotic activity (Drouet et al., 1990; Maubois et al., 1991). Similar to the results of Drouet (1990), the peptides derived from fermentation of Maillard-reacted whey protein concentrates could have shown antithrombotic activities in mice.

The APT induced in mice has been widely used as a model to explore in vivo antithrombotic therapeutic

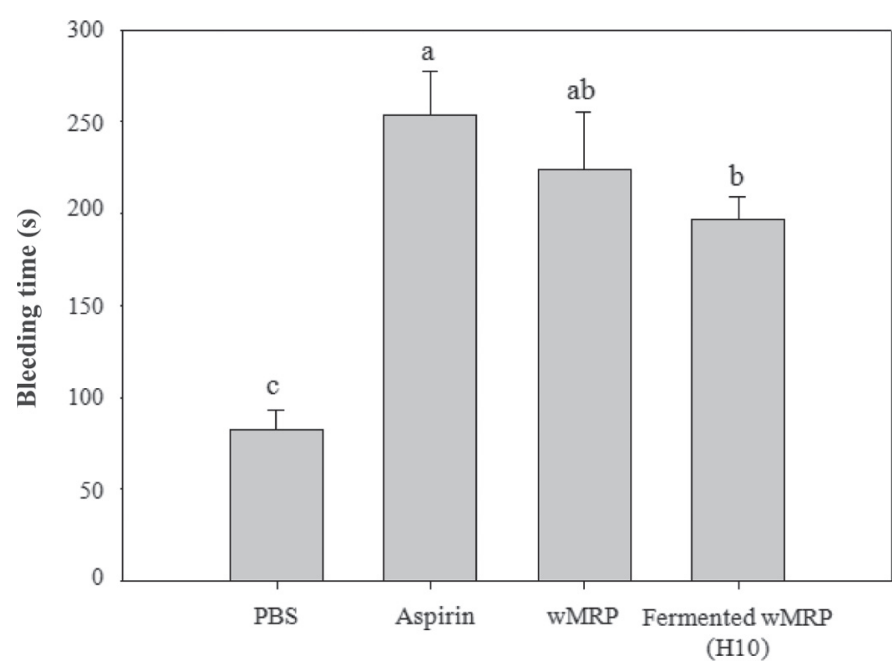

Figure 3. Effect of Maillard-reacted whey protein concentration (wMRP) and fermented wMRP by Lactobacillus gasseri $\mathrm{H} 10$ on bleeding time. Values are expressed as the mean \pm standard deviation $(\mathrm{n}=$ 15). ${ }^{a-c}$ Data with different letters are significantly different $(P<0.05)$. and natural products. A solution of collagen $(114 \mu \mathrm{g})$ and epinephrine $(1.83 \mu \mathrm{g})$ was injected into the tail veins of mice to induce APT. The number of dead or paralyzed mice was counted for $10 \mathrm{~min}$. As shown in Table 3, in the PBS (control) group, the induction of APT immediately caused an $85.8 \%$ chance of severe body paralysis or death, which corresponds to a $14.2 \%$ protection rate. Conversely, a 1-wk, daily pretreatment of wMRP and F-wMRP increased protection against a thromboembolism attack with rates of 86.6 and $93.3 \%$, respectively. These protection rates were even higher than the rate found in the aspirin group (positive control) at $86.6 \%$.

Although it is well established that aspirin provides effective secondary prevention for ischemic cardiovascular disorders, it can produce hemorrhagic events and upper gastrointestinal bleeding. These considerations have led to the search for novel compounds to suppress platelet aggregation. Based on results from this study, a substitute for aspirin could be produced from milk proteins because the Maillard reaction and fermentation were effective in the prevention of APT.

\section{Determination of Serum Cholesterol Levels and Liver Health}

An unfavorable blood lipid profile and high levels of liver somatic index are other important risk factors for various cardiovascular diseases. Serum cholesterol, triglyceride, AST, and ALT levels were determined to study the effects of H9, cMRP, and F-cMRP in rats on a high-cholesterol diet. Figure 4 presents the effects of dietary intake of MRP and fermented MRP on serum cholesterol and triglyceride levels, as well as on AST and ALT. Hypercholesterolemia was confirmed in rats fed an HCD by an increase in the serum total cholesterol, LDL cholesterol, and triglycerides, and the serum HDL cholesterol level was decreased compared with rats fed a normal diet. The total cholesterol levels for the groups fed L. fermentum H9, cMRP, and F-cMRP were significantly lower than for the HCD group. Meanwhile, cMRP and F-cMRP showed a statistically similar effect with SV $(34.3 \%)$ as a positive control. The LDL cholesterol levels for 3 treatment groups were significantly decreased by $61.9,60.7$, and $59.5 \%$, respectively, more so than for the HCD group; 
these results were much greater than for the SV group at only $38.7 \%$. Moreover, triglycerides were also significantly decreased by supplementation with H9, cMRP, and F-cMRP compared with the HCD-fed group. In particular, intake of cMRP fermented by $L$. fermentum H9 showed the lowest level of triglycerides, followed by cMRP and H9. However, the HDL cholesterol level of cMRP was significantly lower than the HCD level. The effect on the liver somatic index in the F-cMRP group demonstrated significantly greater effects on the decreased levels of AST and ALT in serum than for the H9 and cMRP groups. In agreement with these results, consumption of fermented dairy products supplemented with $L$. acidophilus has been shown to decrease serum cholesterol concentrations in mice, rats, pigs, and humans (Grunewald, 1982; Jones et al., 1985; Akalin et al., 1997). Khedkar et al. (1993) reported that these effects could act directly on cholesterol in the gastrointestinal tract, making it unavailable for absorption into the bloodstream. In the cMRP and F-cMRP groups, HDL cholesterol was therefore unaffected, total and LDL cholesterol and triglycerides were reduced, and liver health was improved significantly in the group consuming a diet containing cMRP and F-cMRP. In particular, fermentation of cMRP with L. fermentum H9 synergistically decreased the serum levels of triglycerides, AST, and ALT.

\section{mRNA Expression of LDLr, HMGR, and CYP7A1}

The results of reverse-transcription PCR for determining expression levels of various cholesterol-synthesis-associated genes in the livers of rats fed different diets are shown in Figure 5. The ratios of expression levels for the $L D L r, H M G R$, and $C Y P$ Y $A 1$ genes, compared with those of $\beta$-actin, were used for this experiment. The results showed that the cMRP and F-cMRP groups had the ability to regulate gene expression, as the expression of $C Y P^{r} / A 1$ and $L D L r$ was promoted and $H M G R$ expression was downregulated when compared with the HCD group. However, the rats fed $L$. fermentum $\mathrm{H} 9$ alone were not affected by increased expression of $C Y P$ 7A 1, whereas supplementation with F-cMRP and cMRP significantly promoted CYP $7 A 1$ expression by 147 and 131\%, respectively, compared with the HCD group. The result of HMGR expression showed that the HMGR level was suppressed by 13 and $39 \%$, respectively, in groups fed cMRP and F-cMRP compared with the HCD group. Fermentation of cMRP significantly enhanced regulation of the expression of $C Y P^{7}$ A1 and HMGR $(P<0.05)$, although the lowest $H M G R$ expression was observed in the H9 group. The $L D L r$ expression was also significantly increased in the H9, cMRP, and F-cMRP supplementation groups. In order of precedence, supplementation of cMRP promoted CYP7A1 and LDLr levels, and suppressed HMGR levels, in HCD-fed rats. Furthermore, fermented cMRP had synergistically greater effects on regulation of CYP7A1 and HMGR expression compared with the nonfermented cMRP group.

An important enzyme in cholesterol synthesis, $H M G R$ was one of the target genes assessed for cholesterollowering drugs. Rats fed an HCD had significant reductions in HMGR expression because of fermented cMRP. The cholesterol-metabolizing enzymes, LDLr and CYP7A1, were downregulated as well. These results were in accordance with several reports by Nagaoka et al. (2001) suggesting that $\beta$-LG (lactostatin) induced the gene transcription of $C Y P^{r} 7 A 1$. A report by Lovati et al. (2000) suggested a positive modulation of $L D L r$ induced by a specific sequence corresponding to positions 127 to 150 of $\beta$-conglycinin, which is a soy protein peptide. The effect of milk proteins on the regulation of cholesterol-associated mRNA has not been effectively researched at this time. More extensive studies have been conducted on tea catechins or polyphenols and their cholesterol-lowering effects through levels of gene expression. The findings in this study are important, as the effects of milk proteins and their fermented products suggest that the cholesterol-lowering mechanisms of milk protein peptides are related to the regulation of cholesterol synthesis and metabolism associated with gene expression.

\section{CONCLUSIONS}

In the present study, MRP and fermented MRP were investigated for their effects on antioxidant activity and the promotion of cardiovascular health in mice and rats. The expression of antioxidant-associated genes such as $S O D, C A T$, and $G S H-P x$ were increased by cMRP and F-cMRP compared with the HCD; in particular, the mRNA levels of $S O D$ in the F-cMRP rats was synergistically higher than with cMRP. The bleeding times in the mice administered wMRP and F-wMRP were dramatically prolonged, as they were with aspirin (positive control), and over $86 \%$ of mice in the wMRP and F-wMRP groups were recovered from APT. Moreover, cMRP and F-cMRP significantly reduced the levels of serum total and LDL cholesterol, triglycerides, AST, and ALT, but the concentration of HDL cholesterol was not altered. In particular, supplementation with F-cMRP showed a greater reducing effect on triglycerides, AST, and ALT than supplementation with cMRP. As the result of decreased serum cholesterol levels, expression of genes related to cholesterol synthesis and metabolism, such as $C A T, S O D$, and $G S H-P x$, were regulated by cMRP and F-cMRP. Increased $C Y P^{r} 7 A 1$ expression and decreased 
(A)

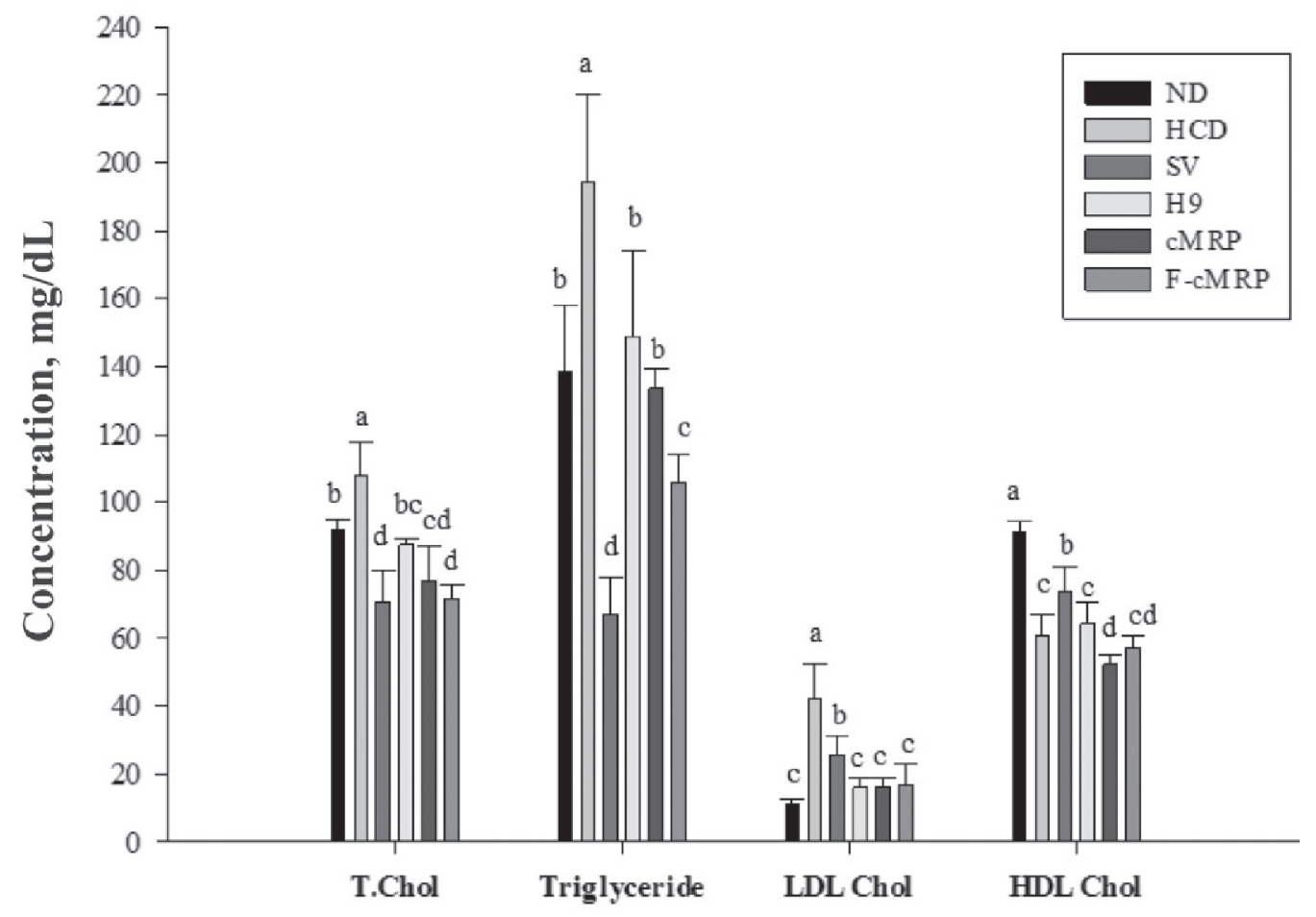

(B)

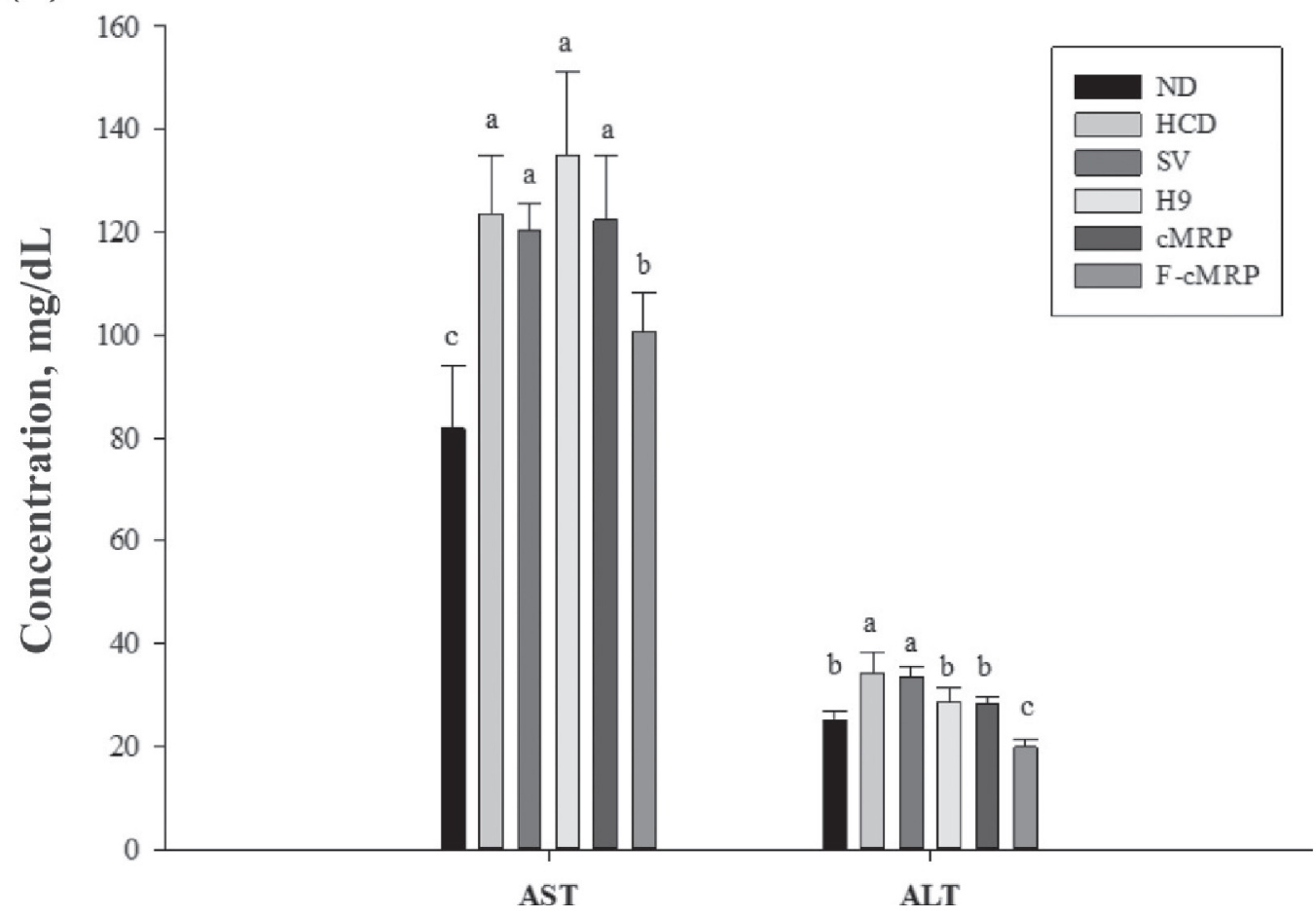

Figure 4. Effect of Maillard-reacted sodium caseinate (cMRP) and fermented cMRP (F-cMRP) by Lactobacillus fermentum H9 (H9) on serum (A) cholesterol (Chol) and (B) liver health levels. Values are expressed as the mean \pm standard deviation $(\mathrm{n}=10) .{ }^{\text {a-d Data }}$ with different letters are significantly different $(P<0.05)$. ND $=$ normal diet; $\mathrm{HCD}=$ high-cholesterol diet; $\mathrm{SV}=$ simvastatin; $\mathrm{T}$. Chol $=$ total cholesterol; LDL = low-density lipoprotein; HDL $=$ high-density lipoprotein; AST $=$ aspartate transaminase; ALT $=$ alanine transaminase. 
(A)
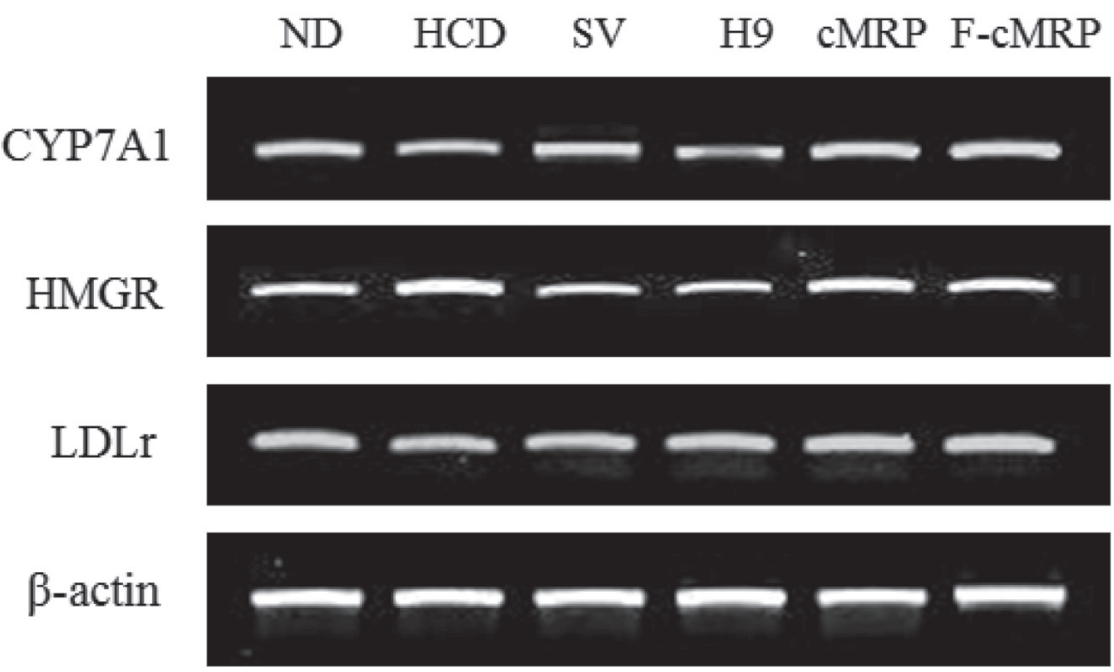

(B)

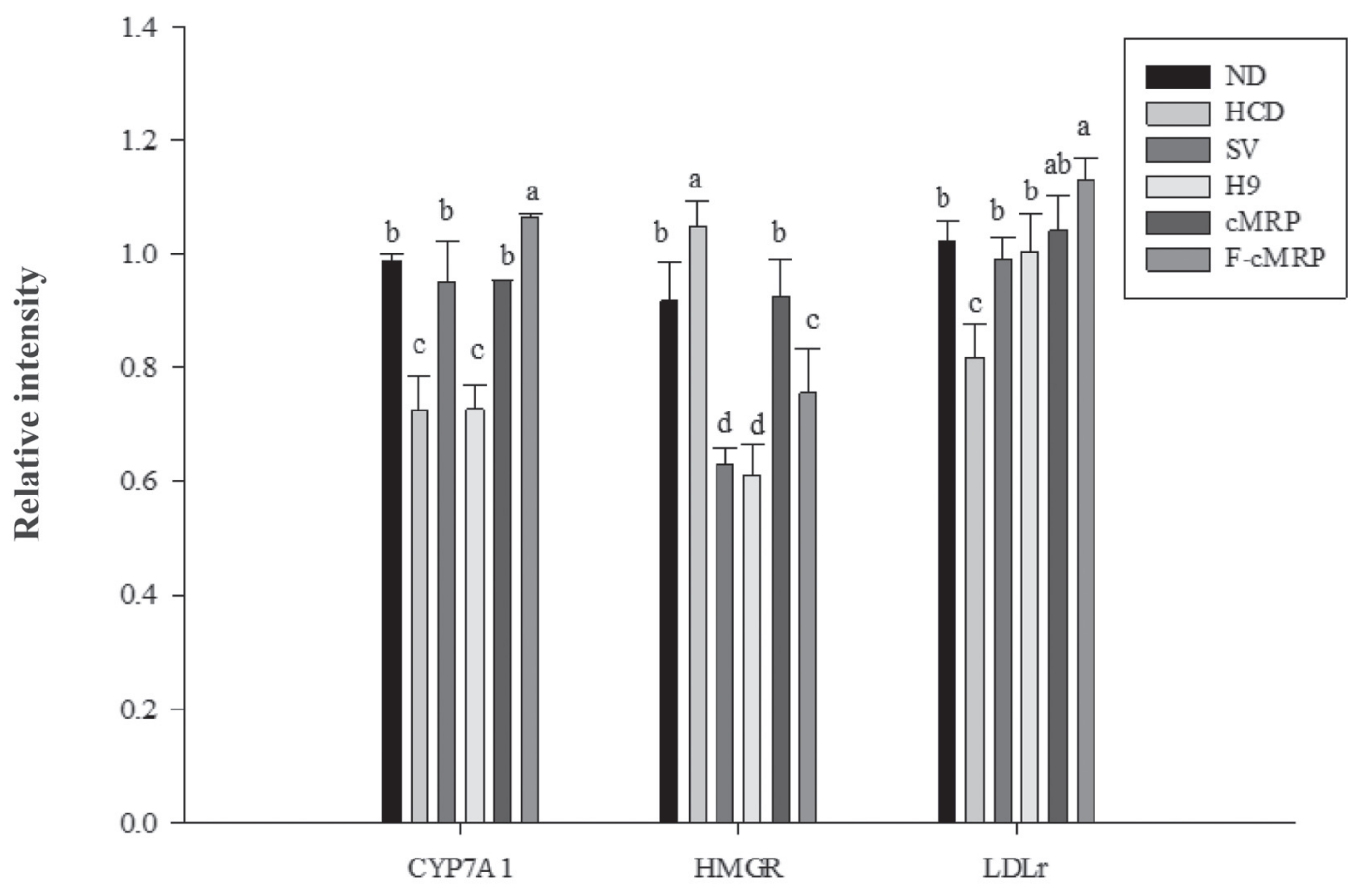

Genes

Figure 5. Effect of Maillard-reacted sodium caseinate (cMRP) and fermented cMRP (F-cMRP) by Lactobacillus fermentum H9 (H9) on expression of cholesterol synthesis and metabolism-associated genes ( $L D L r, H M G R$, and $C Y P$ 7A 1) as (A) semiquantitative reverse-transcription PCR images and (B) relative intensity. Data are expressed as each gene reverse-transcription PCR products normalized to $\beta$-actin products, the arbitrary value of one being assigned to this ratio for ND. Values are expressed as the mean \pm standard deviation $(\mathrm{n}=10)$. ${ }^{\mathrm{a}-\mathrm{d}}$ Data with different letters are significantly different $(P<0.05)$. ND $=$ normal diet; HCD $=$ high-cholesterol diet; $\mathrm{SV}=$ simvastatin.

HMGR expression in the cMRP group was enhanced by supplementation with fermented cMRP. In addition, reduced lipid droplets in liver tissues of the rats fed
F-cMRP, cMRP, and H9 were observed compared with the HCD rats. In this study, the antioxidant and cholesterol-reduction activities of cMRP were promoted by 
fermentation with regulation of several related factors, such as the expression of mRNA and the serum lipid index. Therefore, the potent ability of dietary MRP and fermented MRP to reduce cholesterol levels and cell damage suggests that they might be of preventive and therapeutic benefit to humans with cardiovascular disease.

\section{ACKNOWLEDGMENTS}

This research was supported by the High ValueAdded Food Technology Development Program of the Korea Institute of Planning and Evaluation for Technology in Food, Agriculture, Forestry, and Fisheries (iPET, Gyeonggido, South Korea), and the Ministry for Food, Agriculture, Forestry, and Fisheries of Republic of Korea (Sejong Special Self-Governing City, South Korea; 111137-03-3-SB010).

\section{REFERENCES}

Akalin, A. S., S. Gonc, and S. Duzel. 1997. Influence of yogurt and acidophilus yogurt on serum cholesterol levels in mice. J. Dairy Sci. 80:2721-2725.

Corti, R., V. Fuster, and J. J. Badimon. 2003. Pathogenetic concepts of acute coronary syndromes. J. Am. Coll. Cardiol. 41:7S-14S.

Dejana, E., A. Callioni, A. Quintana, and G. de Gaetano. 1979. Bleeding time in laboratory animals. II-A comparison of different assay conditions in rats. Thromb. Res. 15:191-197.

DiMinno, G., and M. J. Silver. 1983. Mouse antithrombotic assay: A simple method for the evaluation of antithrombotic agents in vivo. Potentiation of antithrombotic activity by ethyl alcohol. J. Pharmacol. Exp. Ther. 225:57-60.

Drouet, L., C. Bal dit Sollier, M. Cisse, G. Pignaud, E. Mazoyer, A M. Fiat, P. Jolles, and J. P. Caen. 1990. The antithrombotic effect of KRDS, a lactotransferrin peptide, compared with RGDS. Nouv. Rev. Fr. Hematol. 32:59-62.

Grunewald, K. K. 1982. Serum cholesterol levels in rats fed skim milk fermented by Lactobacillus acidophilus. J. Food Sci. 47:2078-2079.

Hepner, G., R. Fried, S. St Jeor, L. Fusetti, and R. Morin. 1979. Hypocholesterolemic effect of yogurt and milk. Am. J. Clin. Nutr. $32: 19-24$

Jaspers, D. A., L. K. Massey, and L. O. Luececke. 1984. Effect of consuming yogurts prepared with three culture strains on human serum lipoproteins. J. Food Sci. 49:1178-1181.

Jones, G., K. M. Shahani, and M. A. Amer. 1985. The effect of acidophilus yogurt on serum cholesterol, triglyceride and lipoprotein levels of weaning pigs. J. Dairy Sci. 68:84.

Khedkar, C. D., R. D. Garge, M. J. Mantri, A. M. Patil, B. R. Chavan, and G. D. Khedkar. 1993. Uptake of cholesterol by human strains of Lactobacillus acidophilus. J. Dairy Foods Home Sci. 12:57.
Kim, M. S., and K. A. Lee. 2006. Antithrombotic activity of methanolic extract of Umbilicaria esculenta. J. Ethnopharmacol. 105:342345.

Kuo, C. F., Y. C. Jao, and P. Yang. 2008. Downregulation of hepatic lipoprotein assembly in rats by fermented products of Monascus pilosus. Nutrition 24:477-483.

Lovati, M. R., C. Manzoni, E. Gianazza, A. Arnoldi, E. Kurowska, K. K. Carroll, and C. R. Sirtori. 2000. Soy protein peptides regulate cholesterol homeostasis in Hep G2 cells. J. Nutr. 130:2543-2549.

Maubois, J. L., J. Leonil, R. Trouve, and S. Bouhallab. 1991. Milk peptides with physiological activities. III. Peptides with a cardiovascular effect: Antithrombotic and antihypertensive activity. Lait 71:249-255.

Nagaoka, S., Y. Futamura, K. Miwa, T. Awano, K. Yamauchi, Y. Kanamaru, K. Tadashi, and T. Kuwata. 2001. Identification of novel hypocholesterolemic peptides derived from bovine milk betalactoglobulin. Biochem. Biophys. Res. Commun. 281:11-17.

Nuyts, S., L. Van Mellaert, P. Lambin, and J. Anne. 2001. Efficient isolation of total RNA from Clostridium without DNA contamination. J. Microbiol. Methods 44:235-238.

Oh, N. S., H. S. Kwon, H. A. Lee, J. Y. Joung, J. Y. Lee, K. B. Lee, Y. K. Shin, S. C. Baick, M. R. Park, Y. Kim, K. W. Lee, and S. H. Kim. 2014. Preventive effect of fermented Maillard reaction products from milk proteins in cardiovascular health. J. Dairy Sci. 97:3300-3313

Packham, M. A., and J. F. Mustard. 2005. Platelet aggregation and adenosine diphosphate/adenosine triphosphate receptors: A historical perspective. Semin. Thromb. Hemost. 31:129-138.

Park, Y. H., J. G. Kim, Y. W. Shin, H. S. Kim, Y. J. Kim, T. Chun, S. H. Kim, and K. Y. Whang. 2008. Effects of Lactobacillus acidophilus 43121 and a mixture of Lactobacillus casei and Bifidobacterium longum on the serum cholesterol level and fecal sterol excretion in hypercholesterolemia-induced pigs. Biosci. Biotechnol. Biochem. 72:595-600.

Ramesh, E., T. Jayakumar, R. Elanchezhian, M. Sakthivel, P. Geraldine, and P. A. Thomas. 2009. Green tea catechins, alleviate hepatic lipidemic-oxidative injury in Wistar rats fed an atherogenic diet. Chem. Biol. Interact. 180:10-19.

Renju, G. L., G. Muraleedhara Kurup, and V. R. Bandugula. 2014. Effect of lycopene isolated from Chlorella marina on proliferation and apoptosis in human prostate cancer cell line PC-3. Tumour Biol. 35:10747-10758

Wang, H. H., T. M. Hung, J. Wei, and A. N. Chiang. 2004. Fish oil increases antioxidant enzyme activities in macrophages and reduces atherosclerotic lesions in apoE-knockout mice. Cardiovasc. Res. 61:169-176.

Wang, Y. Z., C. L. Xu, Z. H. An, J. X. Liu, and J. Feng. 2008. Effect of dietary bovine lactoferrin on performance and antioxidant status of piglets. Anim. Feed Sci. Technol. 140:326-336.

Wat, E., S. Tandy, E. Kapera, A. Kamili, R. W. Chung, A. Brown, M. Rowney, and J. S. Cohn. 2009. Dietary phospholipid-rich dairy milk extract reduces hepatomegaly, hepatic steatosis and hyperlipidemia in mice fed a high-fat diet. Atherosclerosis 205:144-150.

Witztum, J. L. 1991. The role of oxidized LDL in atherosclerosis. Adv. Exp. Med. Biol. 285:353-365.

Xu, R., N. Liu, X. Xu, and B. Kong. 2011. Antioxidative effects of whey protein on peroxide-induced cytotoxicity. J. Dairy Sci. 94:3739-3746. 